\title{
OS FUNDAMENTOS TEÓRICOS DA DIDÁTICA DA HISTÓRIA E SUA APLICAÇÃO NO ENSINO ESCOLAR DA HISTÓRIA
}

\author{
HE THEORETICAL FOUNDATIONS OF THE DIDACTICS OF \\ HISTORY AND ITS APPLICATION IN SCHOOL TEACHING OF \\ HISTORY
}

\author{
Luiz Carlos Bento ${ }^{1}$ \\ Carina Bonny ${ }^{2}$
}

\begin{abstract}
RESUMO: Este artigo reflete sobre os fundamentos teóricos da didática da história com base nos estudos de Jörn Rüsen e Klaus Bergmann. A teoria da história proposta em seus textos nos possibilita pensar o conhecimento histórico como fruto de uma teia de fatores que interagem subjetivamente num sujeito portador de uma consciência histórica que se forma através de processos complexos. Dessa forma, a didática da história, deve se preocupar com o lugar do saber histórico proposto pelo ensino de história na formação da consciência histórica dos indivíduos, mas chamando atenção para o fato de que as aulas de história e até mesmo a escola, representam apenas uma pequena parcela da consciência histórica do indivíduo.
\end{abstract}

PALAVRAS-CHAVE: Teoria; Didática da História; Ensino de História

\begin{abstract}
This article reflects on the theoretical foundations of the didactics of history based on studies of Jörn Rüsen and Klaus Bergmann. The theory of the story proposal in their texts enables us to think about the historical knowledge as a result of a web of factors that interact subjectively in a subject carrying a historical awareness which is formed through complex processes. In this way, the teaching of history, must be concerned with the place of history proposed by the teaching of history in the formation of the historical consciousness of individuals, but calling attention to the fact that the lessons of history and even the school, represent only a small portion of the historical consciousness of the individual.
\end{abstract}

KEYWORDS: Theory; Didactics of history; History teaching

\section{Introdução}

Este texto objetiva refletir sobre a didática da história e busca compreender a sua importância no ensino escolar da História ${ }^{3}$. Dessa forma, partiremos do pressuposto de

\footnotetext{
${ }^{1}$ Universidade Federal do Mato Grosso do Sul - luizc.bento@yahoo.com.br

${ }^{2}$ Universidade Federal do Mato Grosso do Sul- karen bonny@hotmail.com
} 
que para qualificar o aprendizado e o ensino escolar da história deve-se antes disso entender o que significa aprender com a história, questionando os processos complexos de formação da consciência histórica de alunos e professores dentro e fora do ambiente escolar.

Para tanto, adota-se como perspectiva analítica os estudos dos pensadores alemães Jörn Rüsen e Klaus Bergmann sobre teoria e didática da história. Nossa problemática de pesquisa é pensar a didática da história para entender como o ensino da história enquanto disciplina vem sendo desenvolvido em sala de aula, para buscar a partir dessa analise propostas alternativas para qualificá-lo, tendo a teoria da história como um eixo norteador dessa reflexão.

Inicialmente, apresenta-se um breve relato sobre como a didática é entendida em seu sentido denotativo, para chegar à compreensão de como ela poderia ser entendida e praticada pelos historiadores; num segundo momento abordar-se-á os processos de formação da consciência histórica com base na teoria de Jörn Rüsen e, por último, uma análise da importância de se considerar o aprendizado histórico na vida prática de alunos e professores.

Para avançar em relação aos inúmeros debates teóricos de seu tempo e propor uma perspectiva analítica para a teoria da história que fosse além das visões enciclopédicas que buscavam a partir dos modelos dos manuais, pensar, os resultados obtidos pela pesquisa histórica, fixando as regras gerais da pesquisa histórica e da historiografia de forma esquemática, Rüsen propõe uma reflexão que objetiva compreender a tarefa e a função da teoria da história a partir da compreensão do que ele conceituou como a matriz disciplinar da história. Com esta categoria, ele define e busca compreender o conjunto sistemático de fatores e princípios que são constituintes da ciência da história enquanto disciplina acadêmica especializada.

Essa perspectiva apresenta um superávit analítico em relação a modelos anteriores por buscar compreender dinamicamente as relações de interdependências entre as regras da pesquisa histórica e da historiografia, pois pretende demonstrar que o pensamento histórico é uma característica essencial e definidora do gênero humano,

\footnotetext{
${ }^{33}$ Esse texto foi estruturado a partir das reflexões desenvolvidas na disciplina Fundamentos Teóricos da Didática da História na Especialização em Teoria e Metodologia do Ensino de História do curso de História de Coxim- UFMS.
} 
pois em sua definição o "pensamento histórico instaura-se na carência humana de orientação do agir e do sofrer os efeitos das ações no tempo" (RÜSEN, 2001, p.30). Na perspectiva proposta pelo teórico alemão, são; a partir destas carências de orientação que se torna possível a ciência histórica, que é entendida por ele, como uma resposta inteligível a uma carência de orientação que emerge diretamente de situações comuns da vida humana prática e que são inerentes a todos os indivíduos.

A matriz disciplinar proposta por Rüsen para pensar a tarefa e a função da teoria da história na contemporaneidade apresenta um modelo analítico circular que busca compreender a constituição do pensamento histórico pela teoria da história a partir do entendimento dos interesses e pressupostos que são fundamentais para os homens "se haverem com suas próprias vidas na medida em que a compreensão do presente e a projeção do futuro somente seriam possíveis com a recuperação do passado" (RÜSEN, 2001, p. 30).

Segundo Rüsen a "expressão" interesses deve ser entendida como sendo o ponto de partida em que o pensamento histórico toma na vida humana prática antes de se constituir como ciência especializada, ou seja, o saber histórico como forma de compreensão temporal da experiência humana no tempo emerge diretamente das carências de orientação que surgem das experiências quotidianas, desta forma, ele vincula o pensar historicamente com o existir enquanto ser histórico, condição ontológica do ser no tempo que deve ser entendida como uma constante antropológica do pensamento histórico.

O segundo fator da matriz disciplinar da história pensada por Rüsen surge como resposta às carências de orientação no tempo que reveste o passado de caráter histórico. Nas palavras de Rüsen:

Se as carências de orientação no tempo são dirigidas ao pensamento sobre o passado, então são requeridos critérios de sentido. São estes que regulam os tratos reflexivos dos homens com o seu mundo e consigo mesmos. Eles decidem como deve ser interpretada a mudança do homem e de seu mundo, afim de que se dêem orientações práticas da vida humana no tempo que tenham "sentido", sem o que as carências de orientação não poderiam vir a ser satisfeitas. (RUSEN, 2001, p.31)

Rüsen define essa ordenação do passado como ideias, entendendo que elas "são os referenciais supremos que emprestam significados a ação e a paixão" (RÜSEN, 2001,p.31) Desta forma, aproxima-se da perspectiva weberiana ao entender que o agir 
humano é racional e determinado por significados, o que faz com que toda ação seja motivada a partir de uma relação de valores. Estas ideias (visão temporalmente ordenada do passado) constituem o segundo fator de sua matriz disciplinar, onde o passado como tempo experimentado adquire a qualidade de tempo histórico.

O terceiro elemento constituinte da matriz disciplinar são os métodos da pesquisa empírica, segundo ele, "sem fontes não se pode reconhecer um passado que faça sentido como histórico" (RÜSEN, 2001, p.32), pois é a partir das experiências concretas vividas no passado que as experiências temporais são conformadas historicamente para poderem agir como valores de orientação temporal. Desta forma, a história como ciência não seria possível sem se levar em consideração processos pré e paracientíficos da experiência do passado e é neste momento que os métodos e as regras da pesquisa empírica garantem a especificidade da história, pois é na pesquisa que as experiências do passado, "oriundas de carências e orientadas por interesses, são trabalhadas pela pesquisa pautada por regras metódicas e transformadas em saber histórico com conteúdo empírico” (RUSEN, 2001, p.33)

Dessa forma, o conhecimento histórico (que emerge de interesses oriundos da vida prática e são ordenados a partir de carências de orientação) torna-se cientifico, pois é produzido a partir de métodos de pesquisa empírica (que são regulados metodicamente) e que validam a especificidade epistemológica da ciência da história, cujos resultados exprimem-se através da historiografia (o que os historiadores fazem quando fazem história) para a qual as formas de apresentação desempenham um papel tão relevante quanto o dos métodos para a pesquisa histórica.

Com a análise da importância das formas de representação para a historiografia, Rüsen, atinge o ponto de culminância de sua analise circular dos pressupostos constituintes da matriz disciplinar da história, pois para ele a obtenção de conhecimento histórico empírico a partir das fontes (vestígios que remetem a interesses e ideias oriundas de carências de orientação) que corresponde à fase da pesquisa histórica se expressa na historiografia, que através das formas de apresentação se remetem novamente aos interesses e carências de orientação a partir do qual o saber histórico originou-se como resposta a uma pergunta: 
cognoscitivo expressos historiograficamente - assume funções de orientação existencial que têm de ser consideradas como um fator próprio (quinto e último) de seus fundamentos (...) pois se são carências de orientação que provocam o pensamento histórico e lhe conferem uma função relevante na vida, então a história como ciência e sua pretensão de racionalidade não podem ser explicadas e fundamentadas sem se levar em conta essa função (RUSEN, 2001,p.34).

Estes fatores constituintes da matriz disciplinar que compõe o pensamento histórico científico não apresentam hierarquias, mas sim interdependências múltiplas. E juntos, eles são responsáveis pela construção das especificidades do pensamento histórico construído cientificamente em relação ao pensamento histórico comum. Com a reflexão sobre as funções do pensamento histórico, Rüsen demonstra que a história apreende as mudanças temporais do mundo humano para dar a elas um sentido narrativo que instrumentaliza a compreensão do passado como uma orientação para a ação no presente. Dessa forma, ele demonstra que o conhecimento histórico é um saber "vivo", uma "história viva" diretamente relacionada com as necessidades existenciais dos indivíduos.

Com base neste enunciado, Rüsen defende que uma teoria da história, dinamicamente pensada possui uma função importantíssima no processo de profissionalização disciplinar da história, pois é ela que garante aos historiadores profissionais a capacidade de produzir uma visão de conjunto que garanta a eles a capacidade de enxergar a floresta como um todo, ao invés de se perderem em meio a uma infinidade de arvores, para isso, caberia à teoria da história a tarefa de transmitir aos novos historiadores em formação uma compreensão sólida da especificidade profissional de sua ciência (RÜSEN, 2001).

Neste sentido, a teoria da história deve buscar refletir sobre as carências de orientação constituidoras do pensamento histórico, adquirindo um sentido didático, sobre as especificidades científicas próprias ao campo disciplinar da história e sobre as funções de orientação exercidas pelo saber histórico. Atuando desta maneira, a teoria da história desempenha funções ${ }^{4}$ que são fundamentais para a história científica, e por isso devem ser entendidas nas suas especificidades, mas sem perder de vista o sentido de

\footnotetext{
${ }^{4}$ Rüsen apresenta uma tipologia destas funções (Função propedêutica, Função coordenadora, Função motivadora, Função organizadora, Função de seleção e fundamentação e Função mediadora) relacionando cada uma delas com a produção do saber histórico em relação à pesquisa histórica e a historiografia.
} 
complementaridade que elas exercem no processo de constituição do pensamento histórico científico.

\section{Como pensar a Didática da História e o Aprendizado Histórico com base nas reflexões de Klaus Bergmann e Jörn Rüsen?}

Para compreender a didática da história, partimos inicialmente do significado dessa palavra em seu sentido denotativo como ela é definida segundo o dicionário como a: "arte de transmitir conhecimentos, técnica de ensinar ou parte da pedagogia que trata de preceitos científicos que orientam a atividade educativa de modo a torna-la mais eficiente" (HOUAISS, 2001. pg. 22). Porém, quando falamos em didática da história devemos pensar e refletir sobre a didática, indo além do seu sentido denotativo, pois o papel e a função que lhe são atribuídos por Rüsen e Bergmann são bem mais abrangentes do que transmitir conhecimentos e de ensinar, tal como ela é entendida genericamente nas licenciaturas.

Ao tomar o supracitado como um pressuposto de nossa pesquisa, entende-se que a consciência histórica e o aprendizado histórico são partes indissociáveis da didática da história. Segundo Klaus Bergamann;

Refletir sobre a História a partir da preocupação da didática da história significa investigar o que é aprendido no ensino de História (é tarefa empírica da Didática da História), o que pode ser aprendido (é a tarefa reflexiva da Didática da História) e o que deveria ser aprendido é a tarefa normativa da Didática da História. (BERGMANN, 1990, p. 29).

O autor aborda inicialmente a função atribuída a didática para o aprendizado dos estudos históricos. Dessa forma, é possível entender com base no autor supracitado que a função atribuída à didática da história é investigar a consciência histórica e assim regulá-la normativamente, uma vez que essa consciência trata de um fator primordial e essencial nas identidades humanas, tanto em nível individual como coletivo, ou seja, é uma premissa básica desse estudo a crença de que o conhecimento histórico do passado humano é um elemento fundamental na formação do ser humano.

Pensada a partir deste espaço de experiência (a didática da história como disciplina cientifica vinculada ao campo disciplinar da história) ela investiga o processo de ensino aprendizagem de história, abrangendo o processo de formação do indivíduo, grupos e sociedades nas quais ele se insere. Bergmann (1990) em seu estudo clássico 
definiu a didática da história a partir de três funções; a empírica, a reflexiva e a sistemática. Dessa forma:

A didática da história é a disciplina científica que investiga sistematicamente todas as formas da mediação intencional e da representação e/ou exposição de história, sobretudo do ensino de história. Com isso, com nas soluções encontradas até agora para as suas tarefas, a didática se ocupa, sobretudo com a fundamentação da disciplina da história no ensino, no contexto histórico e social, e com a educação e formação intencionais nela contidas. Trata também, por outro lado, da exposição/representação da história feita pelos mass-media e meios de comunicação de massa, como, p. ex; filme, televisão, vídeo, rádio e imprensa (BERGAMANN, 1990, p. 30-31)..

Pelo exposto o papel da didática como disciplina, suas funções e investigações são fundamentais nos estudos históricos, mas deve ser vista e aplicada de forma a incluir nos objetos e caminhos de sua pesquisa empírica também as recepções extraescolares da história, ou seja, levar em consideração a história transmitida ao individuo no decorrer do seu processo de socialização, considerar que o aluno já trás consigo uma bagagem de formação sócio cultural, e consequentemente dentro desse ponto de vista, não podemos continuar atribuindo o papel e a função da didática da história como uma forma rasa de transmissão de conhecimento, mas assim como demonstrou Klaus Bergamann que:

(...) Ela não apenas tematiza a História regulada e disciplinada pela ciência e pelo ensino, mas também abarca a História transmitida no processo de socialização, que não é filtrada por nenhuma disciplina científica. Na medida em que se investiga o significado e a importância do mundo vivido fora das instituições científicas e escolas, sua formação e qualidade e seus efeitos para a formação da consciência histórica, a Didática da Histórica dá uma contribuição fundamental para o conhecimento daquele fator subjetivo transmitido socialmente, que está até um certo grau presenta nos procedimentos epistemológicos de cientistas e estudantes, envolvidos em reconstruir a ação e o sofrimento humanos do passado em vários níveis (BERGMANN, 1990, p. 32).

Com base na teoria da história de Jörn Rüsen entende-se que todo tipo de saber histórico é valido, pois ele atua como uma forma de suprir as carências de orientação humana, ou seja, é a forma como se atribui sentido ao passado que possibilita aos indivíduos se autolocalizarem no presente, entendendo o passado assim como demonstrou Koselleck (2006) como o espaço de experiência, a partir do qual se pode individual ou coletivamente projetar suas expectativas em relação ao futuro.

De uma forma bastante esquemática o aprendizado histórico é compreendido por Jörn Rüsen como sendo: 
(...) um processo mental de construção de sentido sobre a experiência do tempo através da narrativa histórica, na qual as competências para tal narrativa surgem e se desenvolvem. A narrativa histórica pode então, em princípio, ser vista como aprendizado quando, com ela, as competências forem adquiridas através de uma função produtiva do sujeito, com as quais a história será apontada como fator de orientação cultural na vida prática humana. Trata-se de uma significativa orientação da vida prática humana relacionada a três dimensões temporais por meio da visualização do passado, resumidamente formulado em um termo: "competência narrativa" (RÜSEN, $2006 \mathrm{p}, 43)$.

De acordo com o autor, essa carência de orientação é um fator antropológico que nos acompanha ao longo de nossas existências históricas, até chegar há um momento em que para suprir essas carências, buscam-se respostas para as perguntas e indagações existenciais da vida humana. Em outras palavras, essas carências de orientação se transformam em perspectivas questionadoras ao que diz respeito ao passado.

Dessa maneira, se entende a necessidade de compreender o papel da didática da história para além da transmissão de conhecimento, pois o aluno já trás consigo um aprendizado histórico que precisa ser considerado, e para melhor entendimento desse ponto de vista, Rüsen nos auxilia mais uma vez, quando pontua:

(...) Somente quando a história deixar de ser aprendida como a mera absorção de um bloco de conhecimentos positivos, e surgir diretamente da elaboração de respostas a perguntas que se façam aos acervos de conhecimentos acumulados, é que poderá ela ser apropriada produtivamente pelo aprendizado e se tornar fator de determinação cultural da vida prática humana (RÜSEN, 2006 p, 44).

É possível entender com base na teoria da história de Rüsen, que o aprendizado histórico só fará sentido para o ser humano se ele suprir suas carências de orientação, nesse sentido, ele só terá algum sentido se responder as sua indagações e contribuir para seu entendimento no presente, ou seja, a história não pode ser transmitida somente como mera absorção de conhecimentos, mas precisa elaborar respostas para as perguntas presentes no acervo de conhecimentos adquiridos pelo ser humano, pois somente assim poderá se tornar um fator determinante e relevante para a vida prática humana, tornando-se um saber útil e mobilizável para a realização de fins práticos.

Dando maior ênfase a este aspecto prático do conhecimento histórico do passado, Jörn Rüsen pontua que:

O aprendizado histórico seria, no entanto, parcial, quando considerado somente como processo cognitivo. Ele é também determinado através de pontos de vista emocionais, estéticos, normativos, e de interesses. A seus resultados pertence, consequentemente, não somente uma competência para a 
interpretação do passado humano como história, mas também se distinguem a competência estética, a qualidade e a particularidade do passado em sua singularidade e diversidade de circunstâncias presentes, e a competência prática de empregar conhecimento histórico na análise, no julgamento e no tratamento dos problemas do presente (RÜSEN, 2006 p, 45).

Conforme a teoria de Rüsen o aprendizado histórico e a formação da consciência histórica acontecem através da ordenação do passado para orientação no presente, como foi explicitado acima, dessa forma ele ocorre por meio da narrativa histórica, basicamente em quatro fases ou formas típicas de construções narrativas de sentido sobre a experiência temporal, que se configura em quatro maneiras de lidar com a experiência do passado que dão forma ao aprendizado histórico: tradicional, exemplar, crítico e genético.

Essas quatro formas de aprendizado histórico, de acordo com a teoria da história de Jörn Rüsen, estão presentes em qualquer sala de aula e não podem ser entendidas de forma esquemática e hierárquica, pois elas traduzem maneiras distintas de relação com a experiência do passado que são formadoras das consciências históricas de alunos e professores.

Dessa forma, como historiadores é possível afirmar que a percepção critica e genética de sentido, seja a mais adequada para o aprendizado da história acadêmica, mas mesmo o aprendizado da história enquanto ciência não neutralizam outras formas de relação com o passado que emergem de outros campos de saber vindos dos mais variados campos da vida social, neste sentido, enquanto professores de história, temos que aprender a lidar com os mais variados campos de carências sociais, a partir dos quais nossos alunos irão mobilizar o aprendizado do passado aprendidos a partir do seu meio sociocultural

Nesse sentido, entende-se que o objetivo do professor de história é produzir uma compreensão crítica ou genética das experiências sociais de representação do tempo histórico, mas para isso, ele precisa ter a habilidade de dialogar construtivamente com formas menos elaboradas de compreensão da vida humana que são mais elementares na vida social dos indivíduos do que o saber histórico e que estão quase sempre vinculadas às concepções religiosas, políticas e morais e que formam a consciência histórica desses indivíduos fornecendo a eles um sentido a partir do qual eles conseguem se identificar 
no mundo. Por isso, enquanto professores, devemos estar capacitados para dialogar com as mais variadas formas de representação cultural do passado, pois:

(...) na forma de aprendizado da construção tradicional do sentido da experiência temporal, as experiências temporais serão processadas em tradições possibilitadoras e condutoras de ações. As tradições se tornam visíveis e serão aceitas e reconstruídas como orientações estabilizadoras da própria vida prática (RÜSEN, 2006 p, 45).

Dentro desse contexto, podemos entender que esta primeira forma de aprendizado histórico tradicional, se resume a nossa convivência com familiares, com amigos, com a sociedade e com o meio social em que estamos inseridos, ou seja, é o aprendizado transmitido e ensinado por terceiros, e que convivem conosco diariamente, que serão aceitos, reconstruídos como forma de orientação em nossa vida humana prática.

Seguindo essa tipologia o autor nos apresenta a segunda forma de aprendizado histórico:

(...) $\mathrm{Na}$ forma de aprendizado da construção exemplar do sentido da experiência temporal, para além do horizonte de tradições, serão processadas experiências temporais em regras gerais condutoras de ações. Nesta forma de aprendizado se constrói a competência de regra em relação à experiência histórica; os conteúdos da experiência serão interpretados como casos de regras gerais, e formam-se, na interação entre generalização de regras e isolação de casos, como condição necessária para um emprego prático na vida da adquirida competência de regras de juízo (RÜSEN, 2006 p, 46).

Nesse nível de aprendizado podemos entender que o ser humano inicia um processo de contestação para além da tradição, para além do aprendizado tradicional que permeia sua existência. Inicia-se nesse momento um processo de autorreflexão sobre o aprendizado adquirido, os conteúdos da experiência conforme pontua Rüsen, serão interpretados como casos de regras gerais, ocorrendo assim à isolação de casos, como uma condição necessária para o emprego prático da vida humana, onde o individuo passa a se orientar a partir de exemplos que direcionam o seu agir racional no mundo.

Dando sequência em nossa reflexão sobre essa tipologia da formação da consciência histórica proposta por Jörn Rüsen, chegamos à terceira forma de aprendizado histórico, onde ele pontua que: 
afirmado modelo de interpretação da vida prática será anulado e será feito valer as necessidades e interesses subjetivos. $\mathrm{O}$ aprendizado histórico serve aqui à obtenção da capacidade de negar a identidade pessoal e social do modelo histórico afirmado (RÜSEN, 2006 p, 46)..

Nesse nível de aprendizado o individuo inicia um processo de autocrítica com relação as suas experiências temporais. Esse procedimento pode ser entendido como uma nova interpretação do modelo de vida prática, sendo que este será anulado e assim serão efetivados outras necessidades e outros interesses. $\mathrm{O}$ aprendizado histórico nesse momento auxilia na obtenção da capacidade de negar a identidade pessoal e também social do modelo histórico até então firmado e reconstruído pelo ser humano.

Dentro dessa abordagem seguimos para a quarta e última forma de aprendizado histórico proposta por Jörn Rüsen em sua tipologia das formas de aprendizado histórico pela via da construção narrativa de sentido, em que:

(...) $\mathrm{Na}$ forma de aprendizado de construção genética do sentido da experiência temporal serão empregadas experiências temporais em temporalizações da própria orientação das ações. Os sujeitos aprendem, na produtiva aquisição da experiência histórica, a considerar sua própria auto relação como dinâmica e temporal. Eles compreendem sua identidade como "desenvolvimento" ou como "formação", e ao mesmo tempo, com isso, aprendem a orientar temporalmente sua própria vida prática de tal forma que possam empregar produtivamente a assimetria característica entre experiência do passado e expectativa de futuro para o mundo moderno nas determinações direcionais da própria vida prática (RÜSEN, 2006 p, 46).

Nessa forma de aprendizado histórico, o individuo adquire o ápice do aprendizado, pois aprendem através da aquisição da experiência histórica, a considerar sua autorrelação como dinâmica e temporal. Aprendem a orientar temporalmente suas próprias vidas, ou seja, conseguem estabelecer a simetria entre as experiências do passado e a expectativa de futuro.

De acordo com os debates e experiências vividas em sala de aula, é possível concluir que para cada modelo opera-se uma perspectiva de ordenamento do passado através da elaboração de sentido da narrativa histórica, que atribui significado a experiência temporal estabelecendo relações entre experiências e expectativas.

Assim no dia a dia de nossa atuação como professores nas escolas, torna-se necessário pensar e considerar o aprendizado histórico e a consciência histórica de cada indivíduo, conduzindo o aprendizado da história científica de maneira reflexiva, investigativa, conduzindo assim o aluno a pensar sobre a sua própria condição social e 
instigar sua capacidade de reflexão crítica da sociedade em que está inserido. Uma vez que, de acordo com Rüsen, podemos entender que o aprendizado histórico escolar só será valido para o aluno se ele fizer alguma diferença em sua vida prática, caso contrário não fará nenhuma diferença para ele.

Por isso, pensar a Didática da História como mera transmissão de conhecimento é preocupante, pois de acordo com os historiadores Rafael Saddi (2012) e Luis Fernando Cerri (2001)

A redução da Didática da história ao ensino escolar da história é, (...) extremamente preocupante, posto que afeta a percepção ampla do modo como os homens se relacionam de forma viva com o passado em uma sociedade, causando, também, uma forma reduzida de entender e praticar o ensino escolar da história. (...) Os alunos e professores também são formados por uma consciência histórica produzida nos meios sociais, e não somente na história produzida na escola (CERRI, 2001, p 216)

Compreende-se com base no anteriormente exposto que é urgente a necessidade de trabalhar a disciplina de história de uma forma reflexiva, para pensar a história para além da sua prática, para além do seu lugar, de maneira a suprir as carências de orientação, uma vez que somos seres temporais e o aprendizado histórico se faz a partir da relação que você estabelece com o passado para a orientação no presente.

O aprendizado histórico é um processo constituinte da consciência humana e ocorre de forma constante ao longo de nossa relação com o mundo social, dessa forma, também é uma responsabilidade central da didática da história pensar esse sentido ontológico da nossa relação com o tempo social numa perspectiva muito mais dinâmica e aprofundada que transcenda os limites de uma mera reflexão sobre meios práticos de ensinar historia como uma disciplina. De acordo com Saddi:

(...) Mesmo quando centra na análise do ensino de história, a didática da história não deve ser compreendida como simplesmente uma 'metódica do ensino de história'. Ao contrário, ela interroga "[...] a necessidade, as intenções e as funções" de se ensinar história nas escolas, "[...] antes de encarar as questões da práxis do ensino (SADDI, 2012, p 216.)

Dessa forma, entendemos que pensada a partir das questões teóricas e epistemologias do campo disciplinar da história, a Didática da história lida diariamente com a teoria, a metodologia e a prática do ensino em história, e esse entendimento nos remete as tarefas que foram pontuadas no tópico anterior que são tanto reflexiva, como empírica e normativa. 
Reflexiva porque analisa as condições e os fundamentos do ensino de história no âmbito escolar; ela também é empírica porque investiga o modo como tem ocorrido o ensino de história, bem como analisa e considera também as ideias históricas de professores e alunos que já trazem, para dentro do ambiente escolar, visões históricas de mundo que atuam como saberes práticos, fornecendo orientação para sua autocompreensão do presente, para que assim possa formular expectativas de futuro.

Entendida deste modo à didática da história também pode assumir uma preocupação normativa, porque além de analisar como tem se desenvolvido o ensino da história como disciplina, também se preocupa em propor reformulações sobre as melhores formas de se ensinar história, constituindo um conjunto pragmático de reflexões sobre o ensino escolar da história que seja capaz de evidenciar a importância da história para vida prática dos alunos.

Dessa forma, é fundamental para se qualificar o ensino escolar da história que os professores sejam capazes de compreender e atuar no meio dessa pluralidade que é o espaço escolar, sendo capazes de compreender historicamente as sutilezas e singularidades dos processos de formação da consciência histórica de alunos e professores. Partindo de uma premissa semelhante o historiador Rafael Saddi nos auxilia nesse entendimento, sobre o aprendizado histórico e a formação da consciência da histórica pontuando que:

\begin{abstract}
Nesse sentido, é preciso refletir sobre os fundamentos e as condições de produção da consciência histórica no ensino de história, bem como ampliar o desenvolvimento de trabalhos que investiguem empiricamente a consciência histórica de alunos e professores; e também, normativamente, encontrar caminhos para o desenvolvimento e a ampliação da consciência histórica a partir do ensino escolar da história. No Brasil, os trabalhos de investigação desenvolvidos a partir da metodologia da educação Histórica, especialmente impulsionados pela professora Dra. Maria Auxiliadora Schimidt na UFPR, têm avançado profundamente na análise empírica da consciência histórica de alunos e professores (SADDI, 2012, p 216.).
\end{abstract}

Na passagem anterior o autor defende que a ampliação da investigação empírica torna-se fundamental no processo de desenvolvimento da tarefa reflexiva e normativa da didática da história no ensino de história. Uma vez que, analisar e compreender a maneira como os indivíduos que se encontram em situação escolar pensam historicamente, nos auxilia a "elaborar teoricamente as condições e os fundamentos do ensino de história" (SADDI, 2012, p 216.). E por outro lado, compreender essas ideias 
históricas tanto de alunos quanto de professores, pode parecer ser uma pré-condição para o bom desenvolvimento de propostas normativas da didática da história no ensino de história. Ou como afirma Jeismann: "Somente em conexão com a 'Morfologia', com a exploração da 'Gênese' e da 'Função' da Consciência Histórica pode uma 'Pragmática' da Didática da História ser suficientemente fundamentada e desenvolvida" (JEISMANN Apud SADDI, 2012, p 217.).

Partindo deste campo de ideias anteriormente expostas, entende-se que para se desenvolver um bom ensino de história, dentro do âmbito escolar é necessário primeiramente compreender como se aprende com a história, para desenvolver os subsídios necessários para construí-la e ensiná-la. Uma vez que, para além do ensino escolar da história como disciplina, a didática da história também lida com os usos públicos da história fora do ambiente escolar, principalmente fora da sala de aula e também fora das narrativas dentro do corpo da academia da ciência da história.

Por isso, segundo esta concepção ampliada de didática da história defendida pelos autores supracitados, se faz necessário considerar e analisar o aprendizado histórico e a consciência histórica que os alunos e professores formam no decorrer de suas vivências em sociedade, para que assim se possa desenvolver um bom ensino de história e ir muito além da transmissão de conhecimentos, mas que vise dessa maneira, que o aprendizado histórico adquirido no âmbito escolar passe a fazer alguma diferença em sua vida prática.

\section{Considerações Finais}

Este texto pretendeu com base em alguns autores estrangeiros e de alguns de seus comentadores nacionais, pensar uma proposta de didática da história que postule ir além do ensino e da aprendizagem em sala de aula, pois, de acordo com a teoria da história de Jörn Rüsen, o aprendizado histórico só fará algum sentido para o individuo se ele suprir as suas carências de orientação, fazendo alguma diferença em sua vida, social, cultural e econômica.

Nesse sentido compartilha-se com Rüsen o postulado de que todo homem sofre de carências de orientação no tempo. Quando os historiadores iniciam um projeto de pesquisa, geralmente eles se perguntam a todo o momento qual é sua relevância social? 
Sabemos que o interesse em se investigar este ou aquele tema histórico não é uma mera função burocrática, mas que esta escolha é subjetiva e está permeada por angústias de nossas experiências vividas no presente, ou por demandas de grupos sociais que participamos ou tivemos algum contato, em algum momento no decorrer de nossas existências, ou por valores ideológicos que partilhamos. Assim concordamos amplamente com os argumentos do historiador Rafael Saddi de que, "os interesses que tornam possíveis o recorte de um tema, o início de uma pesquisa, são elementos didáticos presentes na própria preparação para uma investigação científica da História" (SADDI, 2012, p 218.).

Assim, tal como argumenta Jörn Rüsen (2001), o estudo sobre consciência histórica possibilita compreender o tempo presente diante dos acontecimentos passados em função de um possível futuro. Essa compreensão narrativa do tempo nos instrui como seres humanos, tornando-se assim parte integrante de nossas vidas. Neste sentido, esse seria um processo ontológico que caracteriza a relação do homem com o seu mundo, tenha ele consciência ou não desse processo.

Este artigo teve o intuito de analisar a didática da história, buscando uma compreensão do papel desempenhado em sala de aula para a formação da consciência histórica dos indivíduos, mas chamando atenção para o fato de que as aulas de história e até mesmo a escola, representam apenas uma pequena parcela deste processo. Essa busca teórica visa reivindicar a necessidade de elaboração de um olhar crítico diante das dimensões que o ensino de história pode fornecer, observando que o papel do profissional de história vai além de passar seus conhecimentos, requer muita atenção e dedicação dentro ou fora do ambiente escolar.

Portanto podemos considerar que envolver-se com o ensino de história, é ir além de um aprendizado escolar, é um conhecimento destinado a buscar a compreensão do processo formativo das sociedades humanas no tempo e significa entre outras coisas, a busca por um saber crítico em uma sociedade carente de educação, rica em informação, mas cada vez mais subordinada às precariedades do ensino, por isso nós como estudantes e profissionais do ensino de história, temos a responsabilidade de atuar para desenvolver o melhor papel dentro ou fora dos ambientes formais de 
aprendizagem, o que implica a necessidade de buscar a superação de inúmeras dificuldades estruturais que dificultam esse processo.

Dessa forma, com base na teoria da história de Jörn Rüsen, podemos afirmar que, o aprendizado histórico para o indivíduo só faz algum sentido se ele suprir suas carências de orientação, através da ordenação do passado. Se ele responder também as suas indagações e atender as demandas de orientação no tempo presente, e consequentemente dessa maneira influenciar e fazer alguma diferença em sua vida social e cultural.

Por isso, que a história não pode ser transmitida somente como mera absorção de conhecimentos, mas precisa elaborar respostas para as perguntas e indagações presentes no decorrer da existência de cada indivíduo em sua singularidade. O que nos traz inegavelmente um desafio de repensar os conteúdos que são trabalhados nas aulas de história, adequando-os para as necessidades de alunos e professores. Antes de nos preocuparmos com o quê e como devemos ensinar, precisamos refletir sobre o que significa aprender com a história e qual o sentido deste aprendizado para a vida de alunos e professores.

\section{Referências Bibliográficas}

BARCA, I., MARTINS, E. R., SCHMIDT, M. A. (orgs). Jorn Rüsen e o ensino de história. Curitiba: Ed. UFPR, 2010.

BERGMANN, Klaus. A História na Reflexão Didática. Rev. Bras. De Hist. São Paulo, v. 9, nº 19. pp. 29-42. Set. 89/fev90.

CERRI, Luis Fernando. Ensino de história e consciência histórica. Rio de Janeiro: Editora FGV, 2011.

KOSELlECK, Reinhart. Futuro Passado. Contribuição à semântica dos tempos históricos. Tradução, Wilma Patrícia Maas, Carlos Almeida Pereira; revisão César Benjamin. Rio de Janeiro: Contraponto - Ed. PUC-Rio, 2006. 
RÜSEN, Jörn. Razão histórica: teoria da história: os fundamentos da ciência histórica. Brasília: UnB, 2001.

Didática da história: passado, presente e perspectivas a partir do caso alemão. Práxis Educativa, Ponta Grossa-PR, v.1, n.1, 15 jul./dez. 2006. Tradução de Marcos Roberto Kusnick.

História Viva: teoria da história: formas e funções do conhecimento histórico. Brasília: UnB, 2007.

Aprendizado Histórico. In Didática da história: passado, presente e perspectivas a partir do caso alemão. Práxis Educativa, Ponta Grossa-PR, v.1, n.1, 15 jul./dez. 2006. Tradução de Marcos Roberto Kusnick.. p. 41-49

SADDI, Rafael. O Parafuso da didática da história: o objeto de pesquisa e o campo de investigação de uma didática da história ampliada. Ed: Acta Scientiarum. Education. Maringá, v. 34, nº 2, p. 221-220, July-Dec; 2012 